\title{
EFEITOS DE INTERVENCÕES DOCENTES NA CONDUÇÃO DE UMA ATIVIDADE EXPERIMENTAL EM UM LABORATÓRIO DIDÁTICO DE FÍSICA
}

\author{
Elisabeth Barolli \\ Departamento de Metodologia do Ensino - Unicamp \\ Marisa Franzoni \\ Centro Unisal \\ Campinas - SP
}

\section{Resumo}

$O$ efeito das intervenções docentes foi analisado no contexto de uma aula em que um grupo de estudantes de um curso de graduação desenvolvia uma atividade experimental num laboratório didático de Física. Foram focalizadas algumas das intervenções docentes realizadas no desenvolvimento dessa atividade para, em seguida, tentar compreendê-las no âmbito do que estamos denominando "convites docentes". Esses construtos teóricos foram elaborados tendo como pressuposto a idéia de que, em um processo em que ensino e aprendizagem se articulam, é possível admitir a realização de uma experiência de aprendizagem tanto do ponto de vista de quem ensina como de quem aprende. Nossa análise sobre a situação investigada apóia-se nas proposições de Winnicott acerca do processo inconsciente que caracteriza o progressivo afastamento que a criança realiza em relação à mãe em seu desenvolvimento. Nossos resultados sugerem que não é qualquer intervenção que pode colocar em marcha a articulação entre ensino e aprendizagem e possibilitar novas experiências aos estudantes, bem como ajudá-los a rever suas crenças acerca de um determi-

\footnotetext{
The effect of teachers interventions on experimental activities in a didactic laboratory of Physics

* Recebido: dezembro de 2006.

Aceito: dezembro de 2007.
} 
nado conhecimento. Sugerem, também, que uma experiência de aprendizagem só se configura quando o sujeito investe sua subjetividade no enfrentamento das dificuldades que experimenta em seu processo educativo.

Palavras-chave: Intervenções docentes; experiências de ensino; laboratório didático.

\begin{abstract}
The effect of the teachers' interventions was analyzed in the context of a class where a group of undergraduated course students was carrying out an experimental activity in a didactic laboratory of Physics. The focus was on some of the teachers' interventions during this activity, in order to try to understand them in a scope that we are calling "teachers' interventions". These theoretical constructions were worked out assuming the idea that in a process in which teaching and learning are articulated, it is possible to admit the realization of a learning experience from the point of view of who is teaching and of who is learning as well. Our analysis of the situation studied is supported by Winnicott's propositions about the nonconscious process that characterizes the progressive separation that takes place in a child development concerning his mother. Our results suggest that it is not any kind of intervention that makes possible to start the articulation between teaching and learning, allowing the students to go through new experiences and to help them to review their beliefs about a given knowledge. They also suggest that a learning experience only shows up when the individual invests his/her subjectivity in the difficulties experimented along the educational process.
\end{abstract}

Keywords: Teachers' interventions; learning experience; didactic laboratory. 


\section{Introdução}

Resultados mais recentes de pesquisas na educação em ciências vêm apontando para a relevância de se investigar o processo de construção de saberes, tanto por parte dos aprendizes, como por parte dos professores, com base nos vínculos subjetivos que permeiam as relações de ensino e de aprendizagem. Contribuições dessa natureza estão presentes no trabalho de vários pesquisadores (SANTOS, 1996, 2001; SANTOS; MORTIMER, 1998; VILLANI; CABRAL, 1997; BAROLLI; VILLANI, 1998; ARRUDA et al., 2003; VALADARES, 2002), que têm se inspirado em áreas do conhecimento como a Psicologia, a Psicanálise e a Lingüística na perspectiva de avançar em relação ao paradigma cognitivista, que interpreta o ensino e a aprendizagem como processos que se apóiam exclusivamente em critérios de racionalidade. Os resultados vêm apontando sistematicamente a importância de concebermos esses processos com base em suas vicissitudes, mas, sobretudo, a dificuldade em se vislumbrar caminhos que tenham desdobramentos inequívocos em termos de um sucesso na aprendizagem.

Este trabalho ${ }^{1}$ pretende ser mais uma contribuição no sentido de investigar relações que permeiam as situações de ensino, mas que nem sempre podem ser compreendidas com base em referenciais teóricos que se encontram no campo da cognição. Com essa perspectiva, elegemos um contexto didático criado pelo desenvolvimento de uma atividade experimental num laboratório de Física, buscando explorar e compreender o alcance das intervenções do docente responsável pela condução da disciplina e que procuraram sustentar, explícita ou implicitamente, o envolvimento e as mudanças de um grupo de estudantes em seu processo de aprendizagem. Essas intervenções foram discutidas e problematizadas com base na idéia de convites docentes, um construto teórico que pretende explicitar as possibilidades de articulação entre ensino e aprendizagem.

De modo geral, as questões que orientaram nosso olhar para os eventos que tiveram lugar na situação investigada, podem ser assim sistematizadas: que intervenções docentes foram realizadas durante o desenvolvimento da atividade experimental? Que elementos podem ou não caracterizar essas intervenções como convites docentes?

\footnotetext{
${ }^{1}$ Este trabalho é uma versão modificada de um trabalho apresentado no IX Encontro de Pesquisa em Ensino de Física, EPEF, 2004, realizado em Jaboticatubas, Minas Gerais.
} 


\section{O quadro teórico}

Os convites docentes (FRANZONI, 2004), como construtos teóricos, foram elaborados tendo como pressuposto a idéia de que num processo em que ensino e aprendizagem se articulam, é possível admitir a realização de uma experiência de aprendizagem, tanto do ponto de vista de quem ensina, como de quem aprende. Essa experiência aqui referida se caracteriza pelo enfrentamento, por parte dos sujeitos, de riscos, dificuldades, ansiedades, ilusões e desilusões. Se ela é realizada, certamente seus efeitos serão marcantes, pois nessas circunstâncias o sujeito irá investir, também, sua subjetividade no enfrentamento da situação problema que ele experimenta.

A realização dessa experiência representa para nós o evento de maior relevância no contexto escolar. Parece-nos que as pesquisas na área da Educação e, em particular, da Educação em Ciências Naturais, adquirem significado na medida em que buscam, no ato educativo, investigar e conhecer os elementos que contribuem para que os sujeitos realizem uma experiência de aprendizagem. Quando nos referimos ao professor reflexivo, por exemplo, estamos idealizando um docente que ao refletir sobre sua própria prática realiza uma experiência tal que lhe coloca em uma nova posição em relação ao conhecimento didático-pedagógico, bem como em relação às condições em que esse conhecimento se organiza e se desenvolve. Do ponto de vista do aprendiz, uma experiência como essa também deverá lhe permitir um novo posicionamento frente ao conhecimento em direção a um patamar de maior autonomia em relação ao professor (VILLANI; BAROLLI, 2000). Somente nessas circunstâncias, tanto num caso como no outro, é possível falar na construção de saberes (FREITAS et al., 2000; FRANZONI, 2001). Assim, dentre os principais problemas de pesquisa no campo educacional está justamente a investigação das condições em que a realização de uma experiência de aprendizagem se torna possível.

Os convites docentes foram, então, propostos na perspectiva de formalizar essa questão, pois visam, de modo geral, representar e explicitar o elemento capaz de articular ensino e aprendizagem. Noutras palavras, os convites docentes equivaleriam às estratégias intencionais colocadas em ação pelos professores que, ao entrarem em ressonância com as demandas dos aprendizes, sustentam, explícita e implicitamente, o envolvimento, a persistência, a ousadia e a mudança em seus processos de aprendizagem. Embora a experiência de aprendizagem no contexto escolar esteja colocada como uma relação de mão dupla, estamos admitindo que sua efetivação requer a iniciativa do professor, um pressuposto que a idéia de convites docentes busca expressar. 
Do nosso ponto de vista, são as intervenções do professor que contribuem fortemente para a sustentação dos estudantes em seus processos de aprendizagem. Como propõe Pereira (2002): “o orientador (ou professor) é quem permite que seu aluno se implique ou se envolva com sua proposta de educação enquanto minimamente desejante, deixando a marca de sua particularidade em cada tarefa executada" (p.189). Desse modo, parece-nos razoável supor que a ponte entre o ensino e a aprendizagem possa ser descrita em termos de convites docentes, ou seja, daquilo que coloca em marcha a experiência de aprendizagem.

No caso da formação inicial de professores, por exemplo, os convites feitos aos licenciandos pelo docente de uma disciplina específica tentam, de modo geral, deslocá-los de um padrão de prática do magistério que ele crê e espera poder desenvolver no estágio e em sua vida profissional. Muitos futuros professores chegam aos cursos de Licenciatura acreditando que ensinar é uma atividade de dificuldade apenas razoável. Desse modo, realizam as atividades relacionadas ao estágio com pouca criatividade, tentando reproduzir procedimentos comuns, como quando estudam para uma prova ou preparam um seminário. Diante das tarefas mais desafiadoras, como a exigência do detalhamento do plano de aula ou do objetivo de um projeto de ensino, esperam do docente da disciplina a receita de como devem realizá-las.

Sabemos, no entanto, que não existe um modelo de aula que funcione em qualquer circunstância, o que nos permite prever que os licenciandos terão dificuldades durante o estágio. Ao mesmo tempo, alimentam expectativas quanto ao sucesso de suas aulas; parece-nos que é justamente essa demanda que poderá entrar em ressonância com os convites do docente da disciplina, desde que sejam feitos na tentativa de ajudar o licenciando a transitar entre seus saberes e os do docente, sem o risco de se sentirem à deriva por perceberem a ineficiência de suas estratégias. Os convites docentes tentam, assim, provocar uma ruptura no "modelo" de ensino e aprendizagem do licenciando, ao mesmo tempo em que proporcionam indícios para a construção de um novo modelo. Se as crenças, os valores e os desejos dos licenciandos não são expugnados, os convites estabelecem uma ponte entre o que eles querem de fato em termos do envolvimento de seus alunos com as aulas, e a possibilidade de criar uma nova situação na qual esse envolvimento possa ser ainda maior. Desse ponto de vista, os convites parecem ter o potencial de ajudar na criação a partir do momento que integram o saber do professor à fantasia dos aprendizes. O que se admite é que, em termos das relações que se estabelecem na sala de aula, o saber do docente para os alunos pertence ao campo do concreto, 
isto é, das possibilidades de efetivação de uma nova prática de magistério, enquanto que a fantasia do aprendiz se remete à construção de sua imagem de professor.

Numa outra situação de ensino diferente da formação de professores, os convites docentes no ensino de Ciências, também procuram colocar em marcha a articulação entre ensino e aprendizagem ao desenvolver estratégias que possibilitem aos alunos novas experiências que os ajudem a rever suas crenças acerca de um determinado conhecimento. No entanto, como já procuramos explicitar, não é qualquer intervenção que pode ser vista como convite. O que é, então, necessário acontecer para que o aluno se sinta convidado a participar dessa experiência?

Sem dúvida, essa questão também é procedente nas situações em que o que está em questão é a formação de professores; porém, no caso do presente trabalho, o que se pretende é levantar e explorar as intervenções docentes num laboratório de Física, procurando compreender em que circunstâncias elas podem ser interpretadas como convites docentes.

\section{A situação de ensino investigada}

\section{III.1 O laboratório didático}

A situação de ensino focalizada neste trabalho se refere a uma das aulas de uma disciplina de laboratório de Física para alunos de primeiro ano do Ensino Superior. A disciplina disponibilizava para os alunos um guia, no qual os experimentos encontravam-se descritos em termos dos seus objetivos e procedimentos. Tais procedimentos, em particular, forneciam informações mais detalhadas sobre $o$ experimento, no sentido de orientar os estudantes quanto às grandezas que deveriam medir e também explicitar ou dar pistas sobre os procedimentos necessários para a realização das medidas. Além disso, o guia apresentava uma introdução teórica para situar os alunos quanto ao fenômeno em estudo e quanto aos conceitos físicos aí envolvidos. Havia, ainda, orientações relativas à análise de dados, ao que deveria ser apresentado no relatório e, finalmente, algumas questões cujas resoluções também deveriam constar no mesmo.

Em nossa visão, a disciplina tinha como perspectiva introduzir os alunos aos métodos da ciência, no sentido de trabalhar um conjunto de instrumentos e técnicas experimentais generalizáveis e transferíveis aos diferentes domínios da Física. Assim, o desenvolvimento das atividades privilegiava os conceitos sobre tratamento estatístico de dados em detrimento dos conteúdos da Física envolvidos numa determinada atividade experimental. Sem dúvida, o guia de laboratório e também a professora da disciplina, durante as aulas, apresentavam, em geral, uma 
discussão sobre aspectos físicos dos fenômenos em estudo, mas tais aspectos não eram a tônica no trabalho experimental.

Tanto o arranjo experimental como os instrumentos de medida eram previamente definidos. Além disso, no contexto desse laboratório, a hipótese sobre a qual os alunos trabalhavam era colocada de antemão como um resultado ou conclusão esperada na descrição do fenômeno. Por exemplo: numa das aulas, os alunos realizaram um experimento cujo objetivo, segundo o guia de laboratório, era verificar a equação que descrevia o movimento de queda de objetos em meio viscoso. Aqui, a palavra "verificar" não significava que o estudante deveria julgar a validade de tal equação através da realização do experimento, até porque ela não aparecia como uma hipótese no sentido de conjectura, mas sim como uma relação já estabelecida. Desse modo, a verificação de uma equação passava pela determinação dos parâmetros que a tornariam um bom resultado ou um bom modelo para descrever aquela situação. Para realizar as atividades experimentais, os alunos eram orientados pela professora a se organizarem em duplas que, em princípio, deveriam ser mantidas até o final da disciplina, ou seja, do semestre.

\section{III.2 A atividade experimental analisada}

Em nossa investigação, utilizamos uma câmara de vídeo para apreender as ações de um grupo de dois alunos durante a realização dos experimentos que integraram a disciplina já caracterizada. Certamente, as intervenções feitas pela professora durante a condução da aula, tanto no âmbito da sala toda, como num âmbito mais restrito aos alunos observados, também foram vídeo-gravadas.

Para que fosse possível registrar as imagens da melhor forma, precisamos pedir ao grupo filmado que se posicionasse adequadamente em relação à câmara, porém, sem isolá-lo do restante da classe ${ }^{2}$, procurando, assim, preservar a originalidade da situação de aula, com os grupos próximos entre si. No que diz respeito ao som, utilizamos um microfone direcional sobre a bancada, pois com o instalado na câmara não conseguiríamos registrar com clareza a conversa dos estudantes devido aos ruídos externos à gravação.

A pedido da professora, a câmara foi mantida fixa no laboratório a uma distância de cerca de 3 metros do grupo filmado, de modo que não nos aproximamos dos alunos durante a aula. Com essa providência, era esperado um mínimo de

\footnotetext{
${ }^{2}$ A turma como um todo era constituída por cerca de 25 alunos, organizados em grupos de dois ou três alunos.
} 
interferência no trabalho da classe e é muito provável que isso realmente tenha ajudado os alunos a se "esquecerem" que estavam sendo filmados.

Embora o grupo tenha sido acompanhado durante um semestre, neste trabalho, em particular, nossa atenção está voltada para o primeiro experimento proposto na disciplina, o qual foi realizado pelos estudantes num período de quatro horas. Denominado "Introdução às medidas", o experimento, segundo descrição no guia de laboratório, orientava os estudantes a obterem dados relativos ao período de um pêndulo de comprimento $L$ e comprimento $L / 2$. Ainda de acordo com esse guia, os alunos deveriam "medir o período $\mathrm{T}$ da oscilação, através da cronometragem simultânea, com dois cronômetros digitais, operados pelos integrantes de cada equipe. Anotar os valores no Caderno de Laboratório e comentar possíveis diferenças. Repetir o procedimento, pelo menos, 10 vezes". Os alunos deveriam escolher um valor de $\mathrm{T}(\bar{T})$ que representasse as medidas e tentar representar todos os valores com os algarismos significativos corretos. Finalmente, a partir dessa tomada de dados inicial, o guia sugeria aos alunos que definissem "uma metodologia adequada para prefixar o valor de $\mathrm{L}$ e para determinar $\mathrm{T}$ com precisão melhor. Repetir 50 vezes as medidas para obter o período e escolher um novo valor para $(\bar{T})$. Prefixar $\mathrm{L}^{\prime}=\mathrm{L} / 2$ e obter uma série de medidas de $\mathrm{T}^{\prime \prime}$.

Embora aparentemente simples, o experimento envolvia, em termos da tomada de dados, conceitos como: adequação de um instrumento para realização de uma medida, reconhecimento das flutuações e suas causas, identificação de erros sistemáticos e estatísticos, média como valor representativo de uma série de dados, a repetição de medidas como forma de minimizar erros aleatórios ou estatísticos, apresentação de um resultado com algarismos significativos corretos e noção de incerteza de uma medida.

O valor de L, de $89,1536 \mathrm{~cm}$, foi fornecido no início da aula pela professora e, em termos de instrumentos de medida, os alunos tinham à disposição trena, paquímetro e cronômetro. Certamente, o arranjo experimental disponível jamais permitiria que eles conseguissem essa precisão de medida. As limitações experimentais para a medida do comprimento do pêndulo, bem como para sua cronometragem não foram explicitadas para os alunos, até porque a intenção da professora era justamente discutir, no decorrer do experimento, "alguns percalços no processo de medição" dessas duas grandezas, como afirmava o próprio guia de laboratório. 


\section{A reconstrução da história do experimento e os procedimentos de pesquisa}

Em nossa visão, a história da atividade experimental focalizada pode ser reconstruída por meio de uma análise preliminar que pretende descrever, explicitar e organizar um conjunto de eventos marcantes que tiveram lugar naquele contexto. Essa reconstrução fornece uma história com um recorte essencialmente objetivo, em que as ações dos participantes e as intervenções docentes são articuladas numa provisória influência recíproca, deixando para a fase sucessiva o questionamento dessas relações. É com base nessa história que os nossos dados serão parcialmente selecionados.

Como também nos interessa explorar as intervenções docentes que procuraram sustentar, explícita ou implicitamente, as mudanças do grupo de estudantes durante a realização de sua tarefa, a seleção de nossos dados também foi orientada pela perspectiva de captar elementos da dinâmica de trabalho dos estudantes que pudessem fornecer indícios de que as estratégias colocadas em ação pela professora produziam efeitos na maneira pela qual os estudantes encaminhavam seu trabalho e sua aprendizagem. O que fizemos, então, foi dividir o trabalho experimental dos estudantes em episódios, representados por um problema fundamental sobre o qual os estudantes se debruçavam para encontrar uma solução, ou mesmo pela busca de um problema do qual eles ainda não tinham clareza. Em outras palavras, os episódios foram sendo definidos a partir de algumas sinalizações representadas, para nós, por uma mudança no assunto em discussão, pela satisfação ou não na conclusão de uma tarefa, pela busca de uma atividade que lhes permitisse dar continuidade ao experimento, pela maneira como enfrentavam suas dificuldades, pelas suas exigências com relação ao próprio trabalho, pelo modo como interagiam entre si e com o professor e pelos efeitos provocados ou não pelas intervenções da professora. Para que possam ser identificados nesse processo de reconstrução os estudantes serão aqui denominados de Adi e Leo.

No primeiro desses episódios, depois de os estudantes já terem em mãos um conjunto de instrumentos de medida (cronômetro, trena e paquímetro), a professora perguntou para a sala se faltava alguma coisa para que pudessem dar início à atividade. Como não houve uma resposta rápida da sala ela retoma a pergunta dizendo: "falta o que para vocês começarem a atividade?" Uma aluna, então, arrisca falar no comprimento do fio. Tão logo a professora houve essa resposta volta-se para a lousa afirmando: "nós vamos fabricar um pêndulo de 89,1536 cm". 
Os alunos começam, então, a atividade. Um dos alunos do grupo observado dirige-se à professora, que estava próxima, travando com ela o seguinte diálogo:

Adi: - Como a gente vai medir esse comprimento?

Professora: - Por que?

Adi: - Tem que ter um paquímetro?

Professora: - Paquímetro? Será que vai dar? (Sorrindo, chama a atenção de Adi para o tamanho de um paquímetro, sugerindo a ele a inadequação desse instrumento para o arranjo.)

Adi: O que a gente vai usar?

Professora: Não sei. (A professora sai de perto do grupo e dirige-se para sua mesa.)

Nesse diálogo a professora parece intencionalmente criar um certo suspense, construído com base em respostas ambíguas, escolhidas para problematizar o assunto, em torno da escolha do instrumento apropriado para construir o pêndulo proposto. Um outro aspecto que pode ser inferido por esse diálogo é que havia disposição dos alunos em enfrentar a tarefa. Essa inferência se sustenta a partir de outros diálogos nos quais os alunos se mostram envolvidos em conseguir alcançar a precisão pedida inicialmente.

No segundo episódio em que os alunos realizam a primeira tentativa de medida, dois diálogos, em particular, chamam-nos a atenção. No primeiro deles Adi diz para Leo: "Acho que tá errado. Pergunta pra ela sobre essa medida que você achou". Pouco tempo depois, esse mesmo aluno pergunta para seu colega se ele "sabe mexer" com o paquímetro. Como Leo não sabia, Adi sugere: "Pede uma instrução, porque é muito importante que a gente consiga medir até o 153. Porque aquilo ali é uma notação científica. Todos são algarismos significativos e dá para medir com instrumento de precisão. Só o último é que tem que ser avaliado". Assim, parece-nos que, para os alunos, a obtenção do pêndulo proposto pela professora representava um desafio que estavam tentando enfrentar.

Porém, esses diálogos também adquirem importância, pois ocorrem num contexto em que a professora mantém o suspense em torno da questão de como medir esse comprimento. Ainda nesse segundo episódio ela procura deixar claro não só para o grupo observado, mas para toda a classe que, neste experimento o paquímetro não seria necessário, pois ao final de sua explicação afirma: "Mas isso não é tão importante, porque você não vai conseguir [a medida] dentro da fração de milímetro". Momentos depois, ao se dirigir à classe, chama, ainda, a atenção para o algarismo 6 e diz que ele é da ordem de milésimos de milímetros, ou seja, 
de micrometros. Pergunta, então, se "alguém já viu micrômetro a olho nu". Ela mesma responde que ninguém conseguiria instrumental para medir até esta ordem de grandeza na situação do experimento. Termina dizendo: "Não sei se há necessidade da precisão do paquímetro para medir o diâmetro da bolinha". A despeito dessas recomendações da professora que explicitavam a inadequação do paquímetro (e também do micrômetro) para efetuar a medida, o grupo observado insistiu em buscar a precisão proposta inicialmente, mas com uma nova estratégia.

Assim, o terceiro episódio pôde ser caracterizado como aquele em que os alunos definem uma estratégia mais elaborada para realizar a medida do comprimento do pêndulo. Essa estratégia consistia em medir o diâmetro da bolinha com o paquímetro e o restante com a trena. Investiram nessa estratégia durante algum tempo, porém não pareciam muito satisfeitos. Claramente, o grupo sentia dificuldades em trabalhar com os instrumentos de medida ou mesmo com a realização da medida. Adi sugere, então: "A gente não vai conseguir certinho aquela medida 89,153. A gente teria que medir quanto de fio.... É só fazer 89,153 menos aquele 1,09 [raio da bolinha]. [...] Só que com a trena a gente não consegue aquela precisão de medida, entende? Então que conclusão a gente tira disso? Tira que aqui a gente só vai precisar considerar $1 \mathrm{~cm}$. Na trena a gente vai calcular os 88 e estimar os 15 ".

Embora se mostrassem satisfeitos com esse novo plano, não dão continuidade ao trabalho, pois manifestam necessidade do aval da professora. Porém, ela não vai até o grupo, mas dirige-se à lousa perguntando: "Quem não está satisfeito com seu comprimento?". E, logo em seguida, pede para que os grupos, um a um, apresentem o comprimento escolhido.

É nesse momento que o grupo observado tem um novo movimento no sentido de definir, afinal, o comprimento de seu pêndulo. Essa definição se dá com base nos comentários da professora acerca do comprimento fornecido por um outro grupo: $89,1 \pm 0,1 \mathrm{~cm}$. A professora, que se encontrava próxima ao grupo observado, conversa com um outro aluno que apontou para esse valor, perguntando: "A senhora quer um comprimento mais preciso que isso?" Ao que ela responde: "Não. Não quero... Só quero que vocês tenham certeza com o que estão lidando". Foi com base nessa conversa que pudemos delimitar um quarto episódio pois, a partir desse momento, os alunos também adotam aquele mesmo valor para o comprimento de seu pêndulo, como ilustra o diálogo: lousa, diz:

Adi, fornecendo o valor do comprimento para a professora acrescentar na

$-89,1 \pm 0,1 \mathrm{~cm}$ porque esse 1 já é duvidoso. 


\section{Professora:}

- Isso é muito pessoal (referindo-se à estimativa da incerteza).

Adi tenta retrucar alguma coisa com a professora, mas como ela não está prestando atenção a ele, volta-se para seu colega: "Entendeu, cara? Esse mais ou menos 0,1 é por causa da diferença disso aqui (referindo-se à argolinha que servia para amarrar a bolinha ao fio). Depende da precisão do cálculo que a gente faz do diâmetro da bolinha..." Adi parece, assim, tentar se convencer de que a medida era tão precisa quanto a outra que a professora tinha pedido e, além disso, que a incerteza era algo que estava associada ao objeto (no caso, a bolinha) ou aos cálculos que eles haviam feito.

Os dois alunos voltam, então, a medir, um em cada extremidade, o comprimento do fio que se encontrava sobre a mesa. Quando se dão por satisfeitos, Leo vai amarrar o fio no suporte. Demora uns três minutos nessa tarefa, enquanto Adi fica lendo o guia de laboratório. Leo ainda pergunta: "Tá certo? 89? Ao que Adi responde, sem se virar para o colega: "Vírgula 1". O desinteresse de Adi para realizar a medida é evidente.

Esse episódio marca o final de uma etapa do experimento, ou seja, a definição do comprimento do pêndulo, necessária para que fosse possível dar início às medidas do período de oscilação.

O que nos chama a atenção nesses episódios é que, do ponto de vista da compreensão daquilo que se poderia esperar dos alunos em termos de conceitos e noções que seriam aprendidos com a tarefa, nada ou muito pouco se conseguiu. É possível afirmar, inclusive, que o grupo sequer soube o comprimento do pêndulo que, efetivamente, tinha adotado, pois este foi medido fora do arranjo, indicando que os alunos sequer perceberam o que significava, naquelas condições experimentais, medir esse comprimento.

A continuidade do experimento dependia da escolha do ângulo de oscilação que, segundo o guia, deveria obedecer à relação $\frac{\operatorname{sen} \theta-\theta}{\theta} \leq 0,01$.

Essa escolha inaugura o quinto episódio, marcado pelo enfrentamento de nova etapa não menos difícil para os alunos do que a anterior. Embora Adi fornecesse indicações de que parecia ter uma noção razoável do que estava fazendo, o grupo teve longos períodos de espera pela professora, sem conseguir dar continuidade ao trabalho. Leo, em particular, parecia não compreender o que estava fazendo. Os estudantes somente fizeram a escolha do ângulo depois de pedirem a presença da professora várias vezes que os auxiliou a solucionar as questões relativas aos cálculos necessários para terminarem essa etapa do experimento. 
Finalmente, os estudantes, cada um com um cronômetro, como sugerido no guia, posicionaram-se frente ao arranjo para fazer as medidas do período de oscilação, definindo assim o sexto e último episódio. Mediram um período de cada vez e não dez, como indicava o guia; ou seja, que deveriam fazer inicialmente uma única medida de 10 períodos, para depois fazerem 50 medidas de 10 períodos cada uma. A obtenção da primeira medida servia para que a professora comparasse os resultados dos vários grupos. A professora vai para a lousa e pede a eles que forneçam o valor do período obtido na primeira medida, mas eles não conseguem dar. Ela pede, então, para os outros grupos. Leo percebe que existe diferença entre seus valores e os dos outros grupos. A professora continua na lousa conversando com a classe sobre os valores encontrados e a importância de estimar a incerteza no valor do período. Eles ficam ouvindo.

Quando terminam de medir 10 períodos, um de cada vez, Leo chama a professora para perguntar como eles deveriam fazer a média dos resultados, até porque Adi mede sistematicamente períodos maiores que Leo. Não sabem se é para somar tudo, ou não. A professora percebe que eles estavam medindo apenas um período de cada vez e diz que era para medir dez. Em função do horário, pede que eles parem com a primeira medida e comecem a série de 50 . Pede ainda para que eles desconsiderem a primeira oscilação, até para evitar que os valores medidos pelos dois cronometristas ficassem muito diferentes. Contudo, eles realizam toda a tomada de dados do período sem desconsiderar a primeira oscilação e ainda contando em voz alta.

\section{A análise}

Com base no relato desses episódios é possível inferir que a compreensão dos estudantes em relação aos conteúdos que a professora pretendia ensinar foi muito incipiente. Sem dúvida, foi possível notar que, numa ou noutra etapa específica, conseguiram ter alguma clareza no que faziam. Entretanto, em termos dos conceitos mais gerais relacionados com o processo de medição, principal foco da atividade, pode-se afirmar que a articulação entre as etapas do trabalho não se realizou. Ou seja, os estudantes permaneceram por mais de quatro horas dentro do laboratório didático, sem que pudessem explorar as estratégias de ensino colocadas em ação e sem que pudessem realizar uma experiência de aprendizagem.

O encaminhamento de nossa análise requer, no entanto, mais alguns elementos além daqueles já explicitados até aqui. É importante dizer que a professora tinha muita experiência no ensino de laboratório, pois lecionava essa disciplina há 
muito tempo, tendo acumulado muita reflexão sobre diversas questões envolvidas com o laboratório didático, mais especificamente com o tratamento estatístico de dados. Além disso, pela maneira com que conduzia a aula, é possível afirmar que era uma professora muito segura em relação a seu conhecimento. Somavam-se a esse fato outras condições objetivas para que os alunos tivessem oportunidade de se apropriar dos conteúdos daquela aula, tais como: a existência de uma boa infraestrutura para a disciplina, o que incluía apoio técnico; a disponibilização de um guia de laboratório que, embora tradicional e estruturado, trazia informações relevantes para que os alunos pudessem apoiar seu trabalho; um arranjo experimental e um conjunto de instrumentos de medida para cada grupo. Caberia, então, perguntar: o que aconteceu para que esse grupo tenha aprendido muito pouco do que estava previsto durante a aula? Será que todas essas condições e esses saberes não serviram sequer para orientar a aprendizagem dos estudantes? Por que será que o grupo não encontrou seu mote, apesar de todas essas qualidades da professora e do laboratório? Será, então, que pode haver ensino sem que haja aprendizagem?

Em nossa interpretação, o que parece ter acontecido é que um convite docente não se efetivou nessa aula, pelo menos no que se refere à relação entre a professora e o grupo focalizado. Porém, se a aprendizagem dos alunos deixou muito a desejar, seria indevido afirmar que o grupo não investiu esforços no sentido de realizar sua tarefa, já que os vários episódios descritos anteriormente sinalizam com uma busca e com um investimento dos estudantes. Aliás, o que fica muito evidente até o quarto episódio, pelo menos, é a insistência dos alunos em obter a precisão determinada pela professora no início da aula. Dizemos determinada porque não nos pareceu que em nenhum momento a professora tivesse deixado absolutamente explícito o fato de que aquela precisão era incompatível com as condições experimentais existentes.

Qual, então, o sentido de colocar em ação, na sala de aula, uma estratégia que tem subjacente a realização de algo que, do ponto de vista formal, é inconsistente? Essa, inclusive, é uma estratégia que, até certo ponto, é bastante utilizada em sala de aula. A utilização de problemas do tipo armadilhas foi e é um recurso muito comum na perspectiva de levantar as concepções prévias dos estudantes. E, realmente, no caso do grupo focalizado, a estratégia permitiu efetivamente que os alunos explicitassem pelo menos algumas de suas concepções sobre o processo de medição.

Assim, poderíamos arriscar a interpretação de que o grupo observado recebeu e aceitou esse convite no início da aula, quando foi proposto a eles que fizessem a tal medida. No entanto, para que a experiência de aprendizagem se con- 
sumasse, era necessário que a professora sustentasse esse convite. Mas, se assim for, como o convite poderia ter sido sustentado e, também, porque ela não conseguiu sustentá-lo?

Em termos de convite docente, é possível que a professora tenha, num primeiro momento, entrado em contato com a demanda dos alunos e feito o tal convite. Pelo menos no caso do Adi, achamos que sim, pois ele se sente desafiado a obter uma medida com grande precisão e, por isso, persegue tanto essa meta. Era algo que, para ele, fazia sentido. Há, inclusive, um diálogo dele com o colega, no qual ele se refere explicitamente à importância daquela precisão. "Pede uma instrução, porque é muito importante que a gente consiga medir até o 153 ". No entanto, parece-nos que ficou faltando à professora se colocar na posição na qual, junto com seus alunos, estivessem experimentando algo novo. Isso implicaria para ela aceitar seus próprios recuos, seus limites, e não vislumbrar somente aquilo por ela almejado em termos de conhecimento para seus alunos. Ou seja, somente quem experimentou recuar, avançar, retomar, avançar, recuar de novo, consegue dar sustentação para que seus alunos realizem algo semelhante sem que se sintam à deriva.

Talvez, a professora não tenha vivenciado essas situações com relação à estratégia que ela mesma procurou implementar em sua aula, isto é, muito provavelmente, ela não havia elaborado um saber pessoal sobre o que essa estratégia representaria para ela própria. Por isso, para que uma estratégia possa se configurar como um convite, é essencial que algumas questões tenham sido feitas pelo docente: o que essa intervenção poderá representar para meus alunos e para mim? Que ganhos teremos? Que saberes poderão se construir a partir da experiência? Ao que parece, a professora não refletiu ou mesmo vivenciou essas questões, o que explicaria, pelo menos em parte, o fracasso na aprendizagem dos alunos e sua dificuldade em sustentar o convite inicial.

Nossa interpretação apóia-se, ainda, nas proposições de Winnicott (1975) acerca do processo inconsciente que caracteriza o progressivo afastamento que a criança realiza em relação à mãe em seu desenvolvimento.

O autor sustenta que essa adaptação da criança à realidade se repete de maneira análoga todas as vezes que um sujeito se defronta com a passagem de uma situação familiar para uma situação desconhecida, simultaneamente atemorizante e atraente. Podemos encontrar algo semelhante até nos fenômenos grupais, nos quais o processo de desenvolvimento depende do encontro do grupo com um intermediá- 
rio $^{3}$ que compartilhe da situação antiga e nova, constituindo uma ponte facilitadora da mudança (KAËS, 1998).

A partir de uma possível analogia entre o desenvolvimento da criatividade infantil e o desenvolvimento intelectual do aprendiz em seu processo de aprendizagem, perguntamos: que relações podem ser estabelecidas entre o papel dos cuidados maternais, concebidos como a ilusão e posterior desilusão na etapa da separação, e a sustentação docente no processo de desenvolvimento de uma experiência de aprendizagem?

Como mencionado, estamos chamando de convites docentes as intervenções didáticas capazes de estabelecer um elo entre os projetos e as ações efetivas dos estudantes no enfrentamento de uma situação problema. A grosso modo, os convites, inicialmente, tentam ajudar os estudantes a se localizarem diante da atividade em desenvolvimento para, então, facilitar seus modos de interpretar as novas situações a partir da reflexão e da reorganização de suas ações e, finalmente, ajudálos na mobilização necessária para realizar a atividade de forma criativa e original.

A oscilação entre ilusão e desilusão no desenvolvimento emocional do bebê, em analogia ao desenvolvimento da relação com o saber no processo de aprendizagem, é uma fase intermediária ou de transição que, com a ajuda da mãe ou do professor, poderá se configurar numa zona de experiência efetiva. De acordo com Winnicott (1998), a progressão desse crescimento deverá ser assumida pelas figuras paternais; em analogia à nossa situação, entendemos que essa responsabilidade é do professor que utiliza sua experiência na condução da aprendizagem. Tentando um aprofundamento dessa analogia, os convites docentes parecem apresentar algum potencial para alimentar o processo de oscilação entre ilusão e desilusão quando o sujeito precisa lidar com as realidades interna e externa.

Ao nosso ver, a grande ilusão do grupo analisado foi alimentada, tanto pela possibilidade de ter sucesso na obtenção da medida proposta, como pelo próprio esforço que prometia a aprendizagem de algo novo e, ainda, pelo ganho do reconhecimento da professora em alcançar o que ela pedia. No entanto, nenhuma dessas três coisas parece ter acontecido, ou seja, a precisão da medida não era possível de ser obtida nas condições experimentais propostas e a professora, na maioria das

\footnotetext{
${ }^{3}$ O conceito de intermediário é proposto por Kaës como mecanismo de passagem, isto é, como um conector em um momento de ruptura e entre dois espaços heterogêneos, que fornece uma garantia de continuidade entre cada membro e o grupo, ou entre o grupo e a instituição. Esse intermediário, que pode ser inclusive uma idéia, é construído para assegurar os apoios narcísicos necessários para o desenvolvimento, tanto do sujeito, como do grupo.
} 
vezes, não os escutou de forma efetiva, provocando a desilusão do grupo. A intervenção inicial, que deveria ter se constituído num convite docente, não conseguiu se efetivar, ou seja, aquilo que poderia ter sido colocado em marcha, ora morria com a professora, ora morria com os estudantes. Os convites operavam num vazio, pois a professora já havia desistido do convite, enquanto os estudantes esperavam que ela o assumisse e, ainda, que fizesse outros que pudessem recolocá-los na tarefa. Isso explica o fato dos estudantes não ouvirem mais as intervenções da professora e ela as demandas deles. Enfim, uma conversa de surdos e mudos. Retomando a analogia com o desenvolvimento infantil, a professora foi uma mãe dissimulada ou, nas palavras de Freud, uma mãe não suficientemente boa, que se afasta do bebê num momento em que este não localizou nenhum intermediário que fizesse a ponte entre a experiência velha e nova. Assim, os alunos ficaram presos a ela chamando-a a toda hora, para que ela assumisse sua parte no processo e os ajudasse a encontrar esse intermediário criando, assim, condições para que uma experiência de aprendizagem pudesse ter lugar.

\section{Considerações finais}

A análise realizada com base na idéia de convites docentes nos permite afirmar que as intervenções docentes têm uma forte componente de imprevisibilidade. De acordo com Winnicott, a mãe tem o papel de criar uma situação de ilusão para o bebê e, em seguida, uma situação de desilusão. Enquanto a ilusão permite ao bebê sentir que todas as suas demandas estão sendo atendidas pela mãe, a desilusão, quando gradativa, contribui para que o bebê passe a se interessar e a se satisfazer com outros objetos e vínculos, permitindo que ele realize a separação com a mãe sem que com isso sinta-se à deriva. Falhar nessa passagem pode levar o bebê a supor a ausência da mãe. O rompimento é drástico. Isso se afasta da idéia de convite. $O$ convite da mãe tem que ser fiel àquilo com que ela se compromete.

Em analogia, numa situação em que se pretende articular ensino e aprendizagem, o professor, ao fazer uma intervenção, pode criar uma situação de ilusão assim como aquela que parece ter ocorrido na situação analisada. Desse modo, um convite docente é anunciado. O que parece ter acontecido em nosso caso é que a professora desistiu do convite, mas não avisou aos alunos, pelos menos a esses. Muito provavelmente, ela imaginava que, utilizando os "não sei" e deixando os alunos sem chão, ela estaria ajudando a problematizar o processo de medição; no entanto, é possível que ela estivesse em conflito entre sair de um padrão de aulas que ela estava acostumada para tentar alguma inovação. As ambigüidades com que 
ela se dirigiu a esse grupo, faz-nos supor que, por algum motivo, ela mesma não acreditava, implicitamente, nas possibilidades daquela intervenção se tornar um convite. Além da ambigüidade no sentido dos "não sei", cabe destacar que, na condução de sua aula, a professora não conseguiu, como mencionado, falar com clareza aos alunos sobre a impossibilidade de obtenção daquela medida. Se formos nos apoiar no conceito de objeto transicional para aprofundar nossa interpretação, diríamos que a estratégia de ensino sustentada pela idéia de fazer uma medida formalmente errada, não se constituía, para ela, num objeto transicional. A relação com o objeto transicional implica enfrentar certa tensão de ter o conhecimento e lidar com sua ausência; o alívio dessa tensão é somente proporcionado por uma área intermediária de experiência. A relação que a professora parece ter estabelecido com o conhecimento formal não lhe permitiu, naquele momento, conduzir sua prática com base no erro, pois se esse conhecimento é algo a quem ela presta conta, tudo aquilo que foge a ele deve ser evitado. Quando um professor de ciências se vincula a seus alunos dessa forma, ele o faz como aquele que representa o conhecimento científico ou qualquer outro conhecimento tomado como um dogma.

Assim, a estratégia concebida com base no erro, bastante utilizada em diferentes metodologias de ensino, dificilmente poderia ter se configurado como objeto transicional para a professora. Para que ela pudesse explorar esse tipo de estratégia de ensino, precisaria se permitir brincar com a possibilidade de ensinar a partir do erro. Noutras palavras, parece que a professora não acreditou que a estratégia utilizada no início da aula pudesse se constituir num autêntico convite. A sensação de dissimulação que transparece no decorrer da aula, pode ser interpretada como um desconforto da professora em utilizar aquela estratégia.

Frente a isso, a maneira pela qual a atividade foi conduzida criou condições para que os alunos entrassem na desilusão; porém, as intervenções posteriores não alimentaram uma nova ilusão de forma que os alunos pudessem sair de uma situação de inércia passiva (VILLANI; BAROLLI, 2000).

Assim, parece que uma das dificuldades da prática docente é fazer um convite, e sustentá-lo, até que um novo convite possa ser feito, de forma a criar condições para que tanto o professor como os estudantes se impliquem num novo investimento. Além disso, parece-nos que o docente precisa reconhecer que suas intervenções têm um potencial que, tanto pode contribuir para a realização de uma experiência de aprendizagem, como dificultar a aprendizagem de seus alunos. Sem dúvida, não é possível avaliar as conseqüências de uma intervenção, porém, o que nos fica claro é que a responsabilidade do professor na condução e sustentação de suas intervenções não pode ser banalizada. 


\section{Referências}

ARRUDA, S. M.; BARROS, M. A.; LABURÚ, C. E.; VILLANI, A. Articulando os discursos de um professor de Física com a aprendizagem em grupos de estudantes, 2003. In: ENCONTRO NACIONAL DE PESQUISA EM EDUCAÇÃO EM CIÊNCIAS, IV, 2003, Bauru. Atas... (CD-ROM)

BAROLLI, E.; A. VILLANI, A. Laboratório didático e Subjetividade. In: ENCONTRO DE PESQUISADORES EM ENSINO DE FÍSICA, VI, 1998, Forianópolis. Atas... (CD-ROM)

FRANZONI, M. Os pontos de ressonância entre os convites docentes e a construção de saberes na formação inicial de professores. 2004. 153p. Tese (Doutorado em Educação) - Faculdade de Educação, Universidade de São Paulo, São Paulo.

Qual a natureza dos saberes que os licenciandos têm sobre ser um bom professor? In: REUNIÃO ANUAL DA ANPED, 25, 2002, Caxambu. Atas... (CD-ROM)

A evolução de um grupo de estudantes em uma disciplina de Prática de Ensino de Biologia. 1999. 129p. Dissertação (Mestrado em Ensino de Ciências) - Faculdade de Ciências, Universidade Estadual Paulista, Bauru.

FREITAS, D.; VILLANI, A.; PIERSON, A. H. C.; FRANZONI, M. Conhecimento e saber em experiências de formação de professores. In: REUNIÃO ANUAL DA ANPED, 23, 2000, Caxambu. Atas... (CD-ROM)

KAËS, R. O grupo e o sujeito do grupo. Elementos para uma teoria psicanalítica do grupo. São Paulo: Casa do Psicólogo, 1997. 333p.

PEREIRA, M. R. O relacional e seu avesso na ação do bom professor. In: LOPES, L. M. T.(Org.). A psicanálise escuta a educação. Belo Horizonte: Autêntica, 2002. p. 151-194.

SANTOS, F. M. T. Do ensino de ciências como mudança conceitual à fronteira de uma abordagem afetiva. 1996. Dissertação (Mestrado) - Faculdade de Educação, Universidade Federal de Santa Catarina, Florianópolis.

SANTOS, F. M. T. As múltiplas dimensões das interações em sala de aula. 2001. 308p. Tese (Doutorado em Educação) - Faculdade de Educação, Universidade Federal de Minas Gerais, Belo Horizonte. 
SANTOS, F. M. T.; MORTIMER, E. Investigando as interações afetivas nas salas de aula de Química. In: REUNIÃO ANUAL DA SOCIEDADE BRASILEIRA DE QUÍMICA, 1998, Poços de Caldas. Anais...

VALADARES, M. J. As formas e a construção da subjetividade num grupo de professores: análise de uma prática e seus discursos. 2002. 200p. Dissertação (Mestrado) - IFUSP-FEUSP-IQUSP, Universidade de São Paulo, São Paulo.

VILLANI, A.; BAROLLI, E. Um esquema heurístico de análise e interpretação da aprendizagem. In: ENCONTRO DE PESQUISADORES EM ENSINO DE FÍSICA, VII, 2000, Florianópolis, 2000. Atas... (CD-ROM)

VILLANI, A.; CABRAL, T. C. B. Mudança conceitual, subjetividade e psicanálise. Investigações em Ensino de Ciências, Porto Alegre, v. 2, n. 1, p. 43-61, 1997.

WINNICOTT, D. W. O brincar e a realidade. Rio de Janeiro: Imago Editora, 1975. $203 \mathrm{p}$.

WINNICOTT, D. W. Tudo começa em casa. São Paulo: Martins Fontes, 1999, $282 \mathrm{p}$. 